\title{
Stabbing resistance of body armour panels impregnated with shear thickening fluid
}

DOI:

10.1016/j.compstruct.2016.12.056

\section{Document Version}

Accepted author manuscript

Link to publication record in Manchester Research Explorer

\section{Citation for published version (APA):}

Xu, Y., Chen, X., Wang, Y., \& Yuan, Z. (2017). Stabbing resistance of body armour panels impregnated with shear thickening fluid. Composite Structures, 163, 465-473. https://doi.org/10.1016/j.compstruct.2016.12.056

\section{Published in:}

Composite Structures

\section{Citing this paper}

Please note that where the full-text provided on Manchester Research Explorer is the Author Accepted Manuscript or Proof version this may differ from the final Published version. If citing, it is advised that you check and use the publisher's definitive version.

\section{General rights}

Copyright and moral rights for the publications made accessible in the Research Explorer are retained by the authors and/or other copyright owners and it is a condition of accessing publications that users recognise and abide by the legal requirements associated with these rights.

\section{Takedown policy}

If you believe that this document breaches copyright please refer to the University of Manchester's Takedown Procedures [http://man.ac.uk/04Y6Bo] or contact uml.scholarlycommunications@manchester.ac.uk providing relevant details, so we can investigate your claim.

\section{OPEN ACCESS}




\section{Accepted Manuscript}

Stabbing resistance of body ar mour panels impr egnated with shear thick ening fluid

Yue Xu, Xiaogang Chen, Yan Wang, Zishun Yuan

PII:

$$
\text { S0263-8223(16)32421-7 }
$$

DOI: http://dx.doi.org/10.1016/j.compstruct.2016.12.056

Reference: COST 8111

To appear in:

\section{Composite Structures}

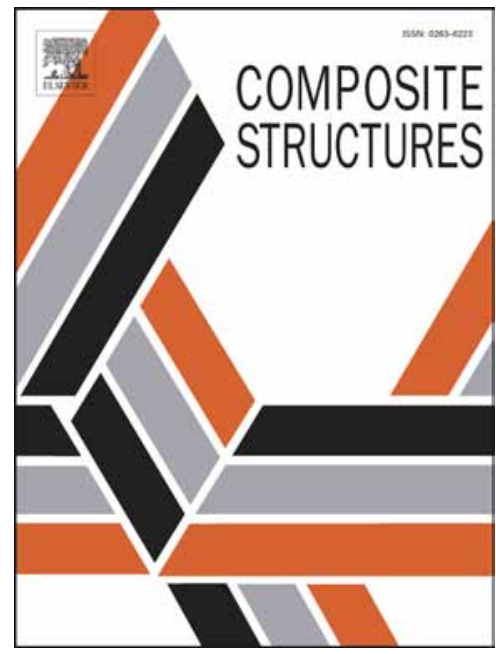

Received Date: 3 November 2016

Revised Date: 8 December 2016

Accepted Date: $\quad 15$ December 2016

Please cite this article as: Xu, Y., Chen, X., Wang, Y., Yuan, Z., Stabbing resistance of body ar mour panels impregnated with shear thickening fluid, Composite Structures (2016), doi: http://dx.doi.org/10.1016/ j.compstruct.2016.12.056

This is a PDF file of an unedited manuscript that has been accepted for publication. As a service to our customers we are providing this early version of the manuscript. The manuscript will undergo copyediting, typesetting, and review of the resulting proof before it is published in its final form. Please note that during the production process errors may be discovered which could affect the content, and all legal disclaimers that apply to the journal pertain. 


\title{
Stabbing resistance of body armour panels impregnated with shear thickening fluid
}

\author{
Yue Xu, Xiaogang Chen", Yan Wang, Zishun Yuan \\ School of Materials, University of Manchester, United Kingdom, M13 9PL \\ * Corresponding Author. Email: xiaogang.chen@manchester.ac.uk
}

\begin{abstract}
This paper presents an investigation on the use of shear thickening fluid (STF) to improve stabbing resistance of soft ballistic body armour. STFs were produced from polyethylene glycol and silica nanoparticles. The effects of silica nanoparticle sizes and silica nanoparticle weight fraction were studied and STFs made with the different compositions were used to impregnate the Twaron ${ }^{\circledR}$ woven fabrics. Systemic investigations into rheological behaviour of STF were carried out experimentally on STFs with different compositions. STF impregnated woven fabric panels were created and tested for stabbing resistance. Stabbing impact tests were conducted on 6 different types of STF impregnated fabric panels against 2 untreated fabric panels, and the results were studied against the benchmark fabrics without STF impregnation. Based on the same number of layers of fabric, the STF impregnation improves the stabbing resistance notably. For same panel areal density, the STF impregnated panels outperform the untreated fabric panel. The results of this research indicate the possibility of lighter ballistic panel materials for higher stabbing protection. It was also found that higher nanoparticle weight fraction and larger nanoparticle size of silica leads to better stabbing resistance performance among the STF impregnated panels.
\end{abstract}

Keywords: stabbing impact, shear thickening fluid (STF), rheological properties, impregnated fabric panels, performance

\section{Introduction}

Body armour for the military is designed to provide protection from the impact of high velocity projectiles such as bullets or bombshell fragments. High performance fibres such as aramid (e.g. Kevlar ${ }^{\circledR}$ and Twaron $^{\circledR}$ ), and ultra high molecular weight polyethylene (e.g. Spectra $^{\circledR}$ and Dyneema ${ }^{\circledR}$ ) have been used for engineering soft ballistic body armours [1]. These high strength, high modulus, high tenacity fibres have resulted in significant improvements in the performance of body armours against ballistic threats [2]. However, it seems that not sufficient attention was paid to the engineering of ballistic body armour for the anti-stabbing performance, which is obviously a serious concern for the body armour users. Anti-terrorist actions and regional conflicts necessitate the further development of protective and flexible armour systems with additional stab-resistant capabilities. Stab threats encountered by the body armour users include direct attacks from knives and sharpened instruments, as well as physical contact with debris, broken glass, and razor wire. The demand for improved protection against stabbing has also been motivated by civilian police forces, particularly in Europe, where restrictions on gun ownership have led to an increase in the proportion of assaults which are committed with knives [3].

Body armour designed with anti-ballistic function is not necessarily resistant to penetration of blades and armour specifically designed to withstand blade penetration is prohibitively bulky and heavy [4]. Hence, fabrication of body armour that provides protection against ballistic 
and stabbing impacts represents a meaningful effort. The major difficulty in improving stabbing resistance of ballistic body armour is that the stabbing resistance mechanisms differ from that for ballistic protection, because of the different impact velocities and different sharpness of the impactors $[3,5]$. Compared with ballistic impact, stabbing impact is more likely to cause stress concentration because of the sharp point and cutting edge of the impactor in the stabbing situation, whilst the material failure against ballistic impact is mostly caused by shear and tensile loading at high strain rate. In most cases, the stabbing impact velocity is in the range of 1 to $20 \mathrm{~m} / \mathrm{s}$, whereas that for ballistic impact 200 to $1,000 \mathrm{~m} / \mathrm{s}$.

Much effort was to improve the stab resistance of ballistic fabrics. Thermal-sprayed hard ceramic coatings were applied to aramid fabrics to enhance stabbing protection [6]. The resulted material demonstrated increased energy absorption during the quasi-static stabbing test, but also added to fabric weight significantly the same time. Aramid fabrics with high yarn count were also developed to provide stabbing (puncture) resistance. However, these high yarn count fabrics were expensive to manufacture and typically resulted in decreases in ballistic protection efficiency of the fabrics [7]. One of approaches to enhance the stabbing resistance is to roughen the surface of fibres or yarns by sanding or corona treatment to achieve higher coefficient of friction. However, such roughening is believed to have limited utility due to the resultant degradation in the fibre [8].

Shear thickening fluid (STF) has attracted attention for impact protection due to its unique viscosity variation subject to impact. STF is a non-Newtonian fluid and shear thickening behaviour is triggered by sudden increase of shear rate to the STF, which causes the colloidal dispersions to be concentrated exhibiting abrupt increase in viscosity. This transforms a liquid dispersion into a solid-like material state [9-11]. Barnes [9] and Brown [12] reported that the shear thickening behaviour of an STF is influenced by many factor factors including the particle size and size distribution, particle shape, polydispersity of the particles, particle concentration, and interactions among particles, as well as the properties of the dispersion medium. The shear rate triggering shear thickening transition is referred to as the critical shear rate, which can be determined by using experimental and theoretical methods. Van der Werff and De Kruif [13] studied the methods to manipulate the critical shear rate and the viscosity increase of STF, and confirmed that lower critical shear rate and amplified severity shear thickening viscosity of STFs can be achieved by using larger particle size and higher particle volume fraction.

Work has been done to investigate impact properties of fabrics impregnated with STFs. It has been reported that STF enhanced fabrics were able to take advantages of STF properties for the enhancement of ballistic performance and stabbing resistance [14-17]. Work on ballistic and stabbing performance of body armour showed that improved impact resistance of STFimpregnated fabrics could be attributed to the shear thickening behaviour [18-19]. The deformation and energy absorption modes of STF impregnated and untreated Kevlar ${ }^{\circledR}$ woven fabrics upon impact was analysed by Majumdar et al. [20], and they reported that in the untreated Kevlar $^{\circledR}$ fabrics, only the primary yarns, directly engaged by the impactor, participated the load sharing and energy absorption, leading to low energy absorption. In case of STF impregnated fabrics, the STF was transformed into a solid-like material upon impact and the transformed STF acts like a bridging matrix that converted the network of yarns in the fabric into a single structure. In this case, the entire fabric rather than only the primary yarns participated in load bearing and energy absorption. The failure of the STF impregnated structure is by rupture of fibres and yarns rather than their slippage. Some other studies 
showed that the enhancement of impact resistance was due to higher inter-yarn friction in the fabric brought by STF with constraining the pull-out of yarns [18, 21-23].

It seems to be clear that STF is able to enhance the performance of the panels against low velocity impact such as stabbing, but the STF impregnation would definitely add weight to the panel. The research described in this paper aimed to investigate the feasibility of lightweight armour panels impregnated with STF. STFs with different constructional parameters were studied for impact behaviour and STF impregnated fabrics and panels were evaluated based on practical experiments for stabbing protection with respect to the areal density of the panels.

\section{Materials and Experiments}

\subsection{Experimental materials}

\subsubsection{Woven ballistic panel materials}

Aramid fibres are popularly used as protective materials for ballistic and stabbing protection. In the chemical construction, aramid has aromatic rings between the amide groups that contribute to the high tensile strength and thermal resistance of the fibres. According to the different orientated chemical linkages, there are meta-aramid (e.g. Nomex ${ }^{\circledR}$ ) and para-aramid (e.g. Kevlar ${ }^{\circledR}$ and Twaron $^{\circledR}$ ), the chemical structure of which are shown in Figure 1. Because of the structural differences, para-aramid fibres demonstrate higher mechanical properties than the meta-aramid fibres.<smiles>CCC(=O)c1cccc(C(=O)Nc2cccc(N(C)C)c2)c1</smiles>

(a) Meta-aramid

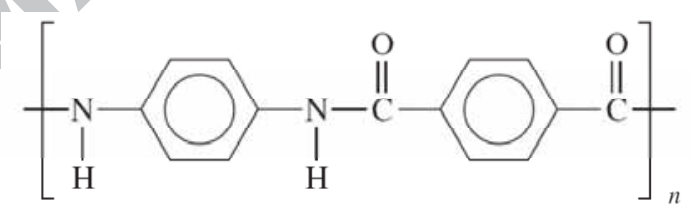

(b) Para-aramid

Figure 1. Chemical structural formula of the two varieties of aramid

In this research, a Twaron ${ }^{\circledR}$ filament yarn was used for producing the plain woven fabric, and the fabric specifications are described in Table 1.

Table 1. Details of Twaron ${ }^{\circledR}$ fabric parameters.

\begin{tabular}{ll}
\hline Fabric structure parameters & value \\
\hline Weave & Plain \\
Areal density $\left(\mathrm{g} / \mathrm{m}^{2}\right)$ & 160 \\
Yarn count $($ tex $)$ & 93 \\
Thread density $(\mathrm{ends}$ and picks per $\mathrm{cm})$ & 8 \\
Fabric thickness $(\mathrm{mm})$ & 0.3 \\
\hline
\end{tabular}

It is necessary to mention that the thread density 8 picks/cm was the optimal results from previous studies with the given yarn count, leading to best ballistic performance [24].

\subsubsection{Preparation of shear thickening fluids}

The STF colloidal dispersions employed in this research were made from silica nanoparticles and PEG (Polyethylene Glycol). In order to explore the performance of shear thickening fluid 
upon shear load, different particle sizes and different particle weight fractions (concentrations) were taken into consideration during the STF preparation.

Two different silica nanoparticle sizes $(650 \mathrm{~nm}$ and $12 \mathrm{~nm})$, supplied by Sigma-Aldrich (Germany), were used in STF preparation. The specific density of the nanoparticles is $36.8 \mathrm{~kg} / \mathrm{m}^{3}$ at $25^{\circ} \mathrm{C}$. For both $12 \mathrm{~nm}$ and $650 \mathrm{~nm}$ particles, three silica weight fractions, $20 \%$, $25 \%$ and $30 \%$, were used in making the STFs. $30 \%$ particle weight fraction was the maximum concentration that was able to achieve for the $12 \mathrm{~nm}$ silica STF because of the higher free surface energy of the $12 \mathrm{~nm}$ silica particles. The same particle weight fractions were adopted for making STFs from the $650 \mathrm{~nm}$ silica particles for comparison purposes. A previous research [13] on critical shear rate showed that high silica particle fraction led to lower critical shear rate and greater increase of shear thickening viscosity, and vice versa.

The STFs were synthesised by intensive mixing of silica nanoparticles in polyethylene glycol (PEG). PEG was chosen as a solvent due to its non-toxicity, low volatility, thermal stability and its ability to form hydrogen bond with the aramid fibres [25]. PEG can be made to have different molecular weight, such as PEG200, PEG400 and PEG600. Park et al. [22] found the molecular weight of PEG would not affect the STF performance significantly, and accordingly only PEG200 was chosen for the current research for the investigation into the nanoparticle size and particle weight fraction. Additionally, PEG200 has the lowest viscosity and is easier for production of STFs. The volume density of PEG200 is $1.127 \mathrm{~g} / \mathrm{cm}^{3}$ [26].

A high speed homogenizer (Silverson L4R homogenizer emulsifier) was used with the speed of $6000 \mathrm{rpm}$ to stir the solution while adding silica powder into the PEG so as to achieve even distribution of particles in the STFs. Ultrasonic wave vibration also was used to improve STF quality. The STFs were placed in a vacuum chamber at room temperature for 24 hours to remove the air bubbles prior to rheological measurement.

\subsubsection{Fabrication of STF-Twaron ${ }^{\circledR}$ composites}

This task aimed to impregnate the Twaron ${ }^{\circledR}$ fabric with the produced STFs. Due to the high viscosity of the STFs, they were diluted with ethanol at a 3:1 volume ratio between ethanol to STF to reduce the surface tension of the STF, so as to wet the fibres in the fabric properly. The Twaron ${ }^{\circledR}$ fabric was cut into rectangular specimens of $12 \mathrm{~cm} \times 24 \mathrm{~cm}$ according to the size of the fabric clamp. Each of the fabric specimens was immersed into the ethanol-diluted STF in a container for one minute, then the impregnated fabric together with the container was dried in a hot air oven at a temperature of $75^{\circ} \mathrm{C}$ to remove ethanol from the fabric. The drying process was carried on until the total weight of the fabric-STF assembly became stabilised. The STF impregnated fabric was removed from the container and the wet fabric was squeezed using a roller to rid the excessive STF from the fabric. The STF impregnated fabric was weighed to ensure a constant STF add-on to the fabric. The weight ratio between the fabric and STF in the samples was optimised to be 50:50 such that the fabric was fully impregnated and the STF was continuous in the fabrics. The prepared specimens were saved in a sealed plastic bag for impact performance tests. The morphologies of the untreated fabric and STF-impregnated fabric were studied by means of scanning electron microscope (HITACHI, S-3000N). SEM images of untreated and impregnated Twaron ${ }^{\circledR}$ fabrics are shown in Figure 2. 


\section{ACCEPTED MANUSCRIPT}

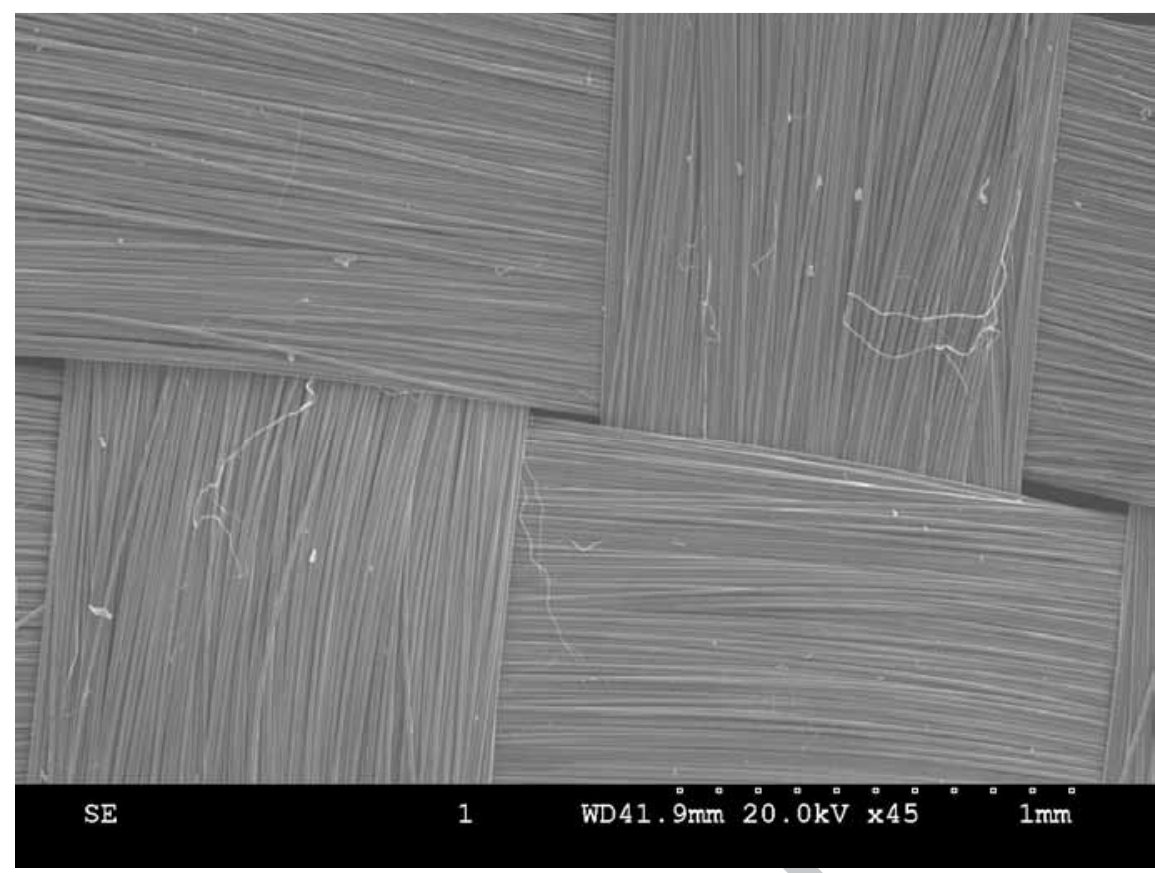

(a) The fabric before STF impregnation

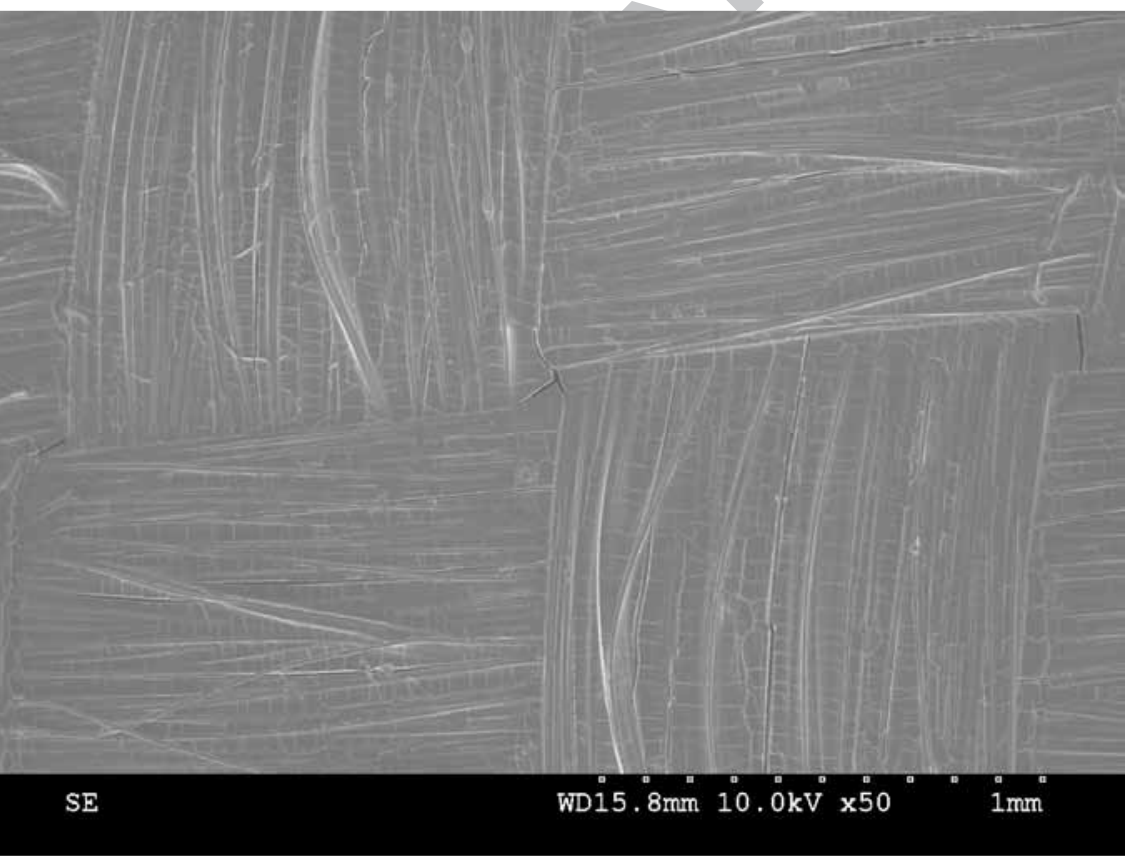

(b) The fabric after impregnation 


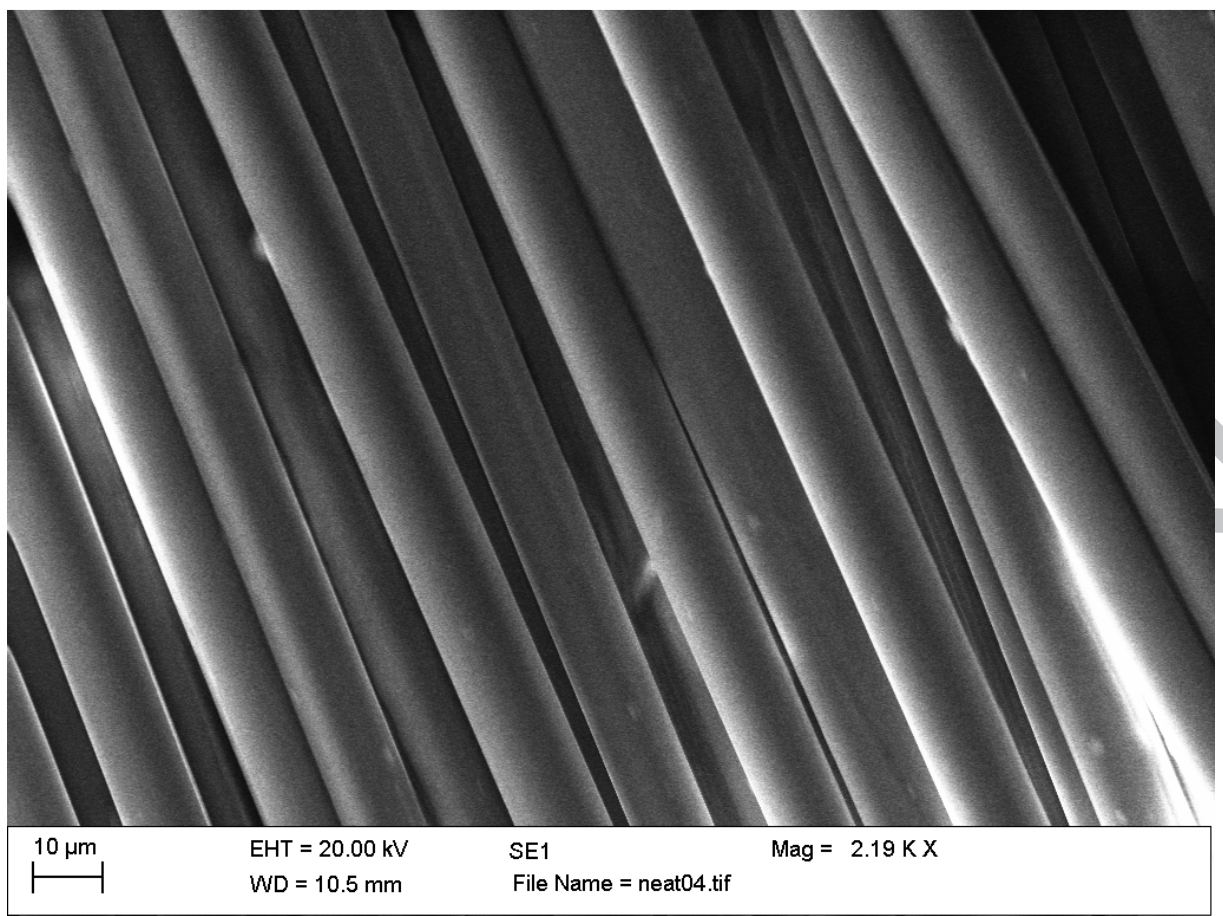

(c) A fibre tow in an untreated fabric

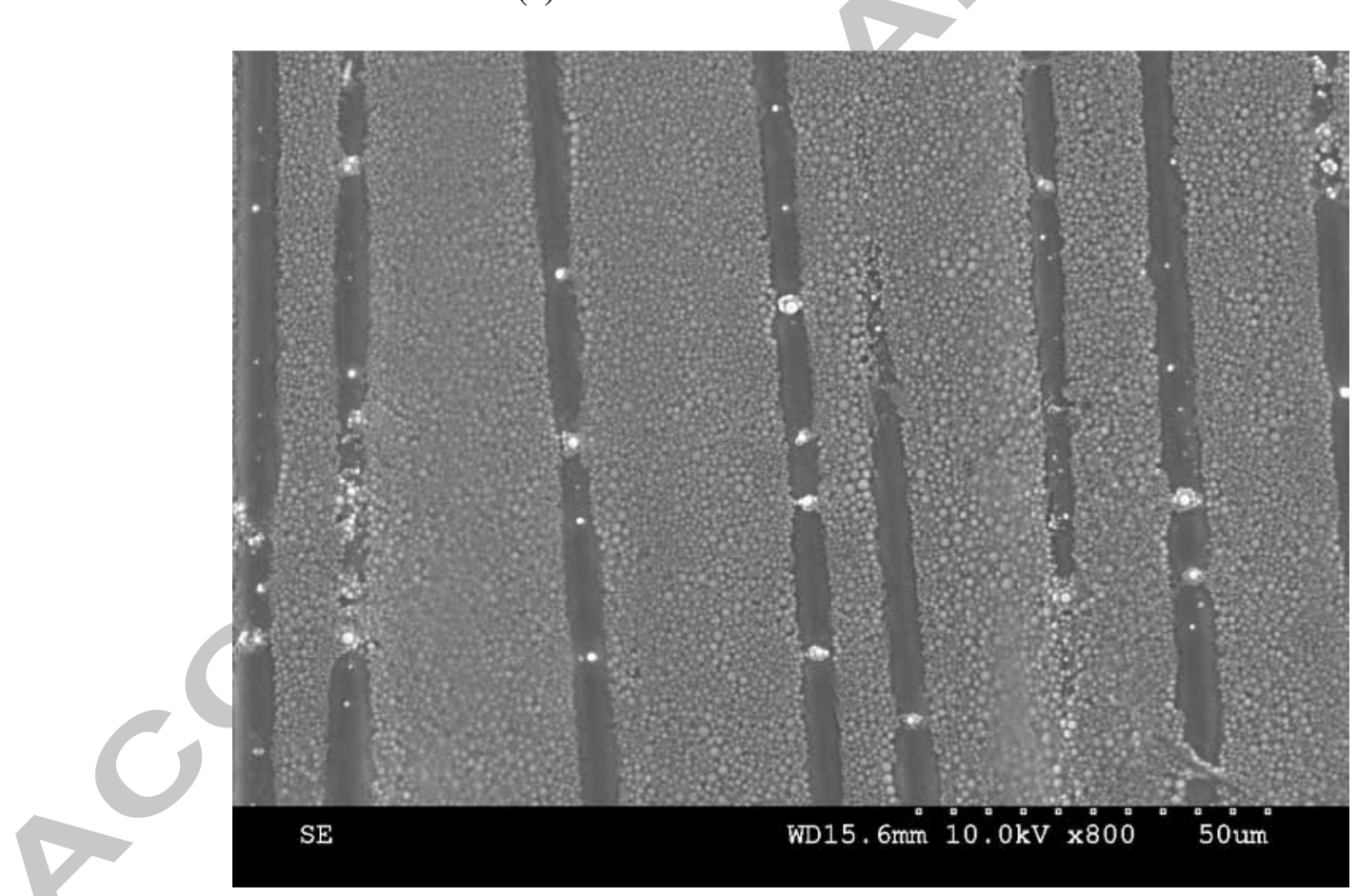

(d) A fibre tow in an STF-impregnated fabric

Figure 2. SEM images of untreated and STF impregnated Twaron ${ }^{\circledR}$ fabrics

Photographs (a) and (b) in Figure 2 contrast the untreated and STF-impregnated fabric, whereas (c) and (d) compares the fibre tows from the untreated and impregnated fabric panels. These SEM images show that the STF was uniformly distributed in the Twaron ${ }^{\circledR}$ fabrics after the impregnation process and achieved full impregnation where the STF was continuous in 
the impregnated fabric panels, which is important and imperative for the STF to work at an impact load.

\subsection{Experimental measurements}

\subsubsection{Rheological measurement of STFs}

The rheological properties of STFs were measured using a stress-controlled rheometer (TA AR-G2) with a cone-and-plate geometry, which is able to provide shear rates from $0.01 \mathrm{~s}^{-1}$ to $1000 \mathrm{~s}^{-1}$. The critical stress value marking shear thickening is affected by the rheometer plate gap interval [27]. In this study, a constant $1 \mathrm{~mm}$ gap interval between the cone and plate was used for the measurement of all the STF samples with the plate diameter being $50 \mathrm{~mm}$, so as to eliminate the effect of the gap size. The measurements took place at the ambient temperature. Different categories of STFs were measured for the relationship between viscosity and shear rate.

\subsubsection{Stab testing of fabric panels}

The stabbing impact testing was performed on Instron Dynatup 8200 drop weight tester, shown in Figure 3. To perform a stab test, the impactor, in this case an P1 knife, was mounted to the crosshead, the total mass of which is $5 \mathrm{~kg}$. The crosshead dropped freely from a fixed height of $0.46 \mathrm{~m}$ to impact the target. The velocity of the crosshead at impact was measured using via flags attached to the frame. Impact resistance to the knife impactor was measured through the load cell mounted on the base of the impactor. The stab targets are placed on multi-layer foams and elastomers backing, as specified by the NIJ standard, to provide a damped response similar to armour mounted on a human torso [28]. The specimens were clamped at four edges using a steel frame fixture with fastening bolts. All fabric layers were oriented in the same direction.

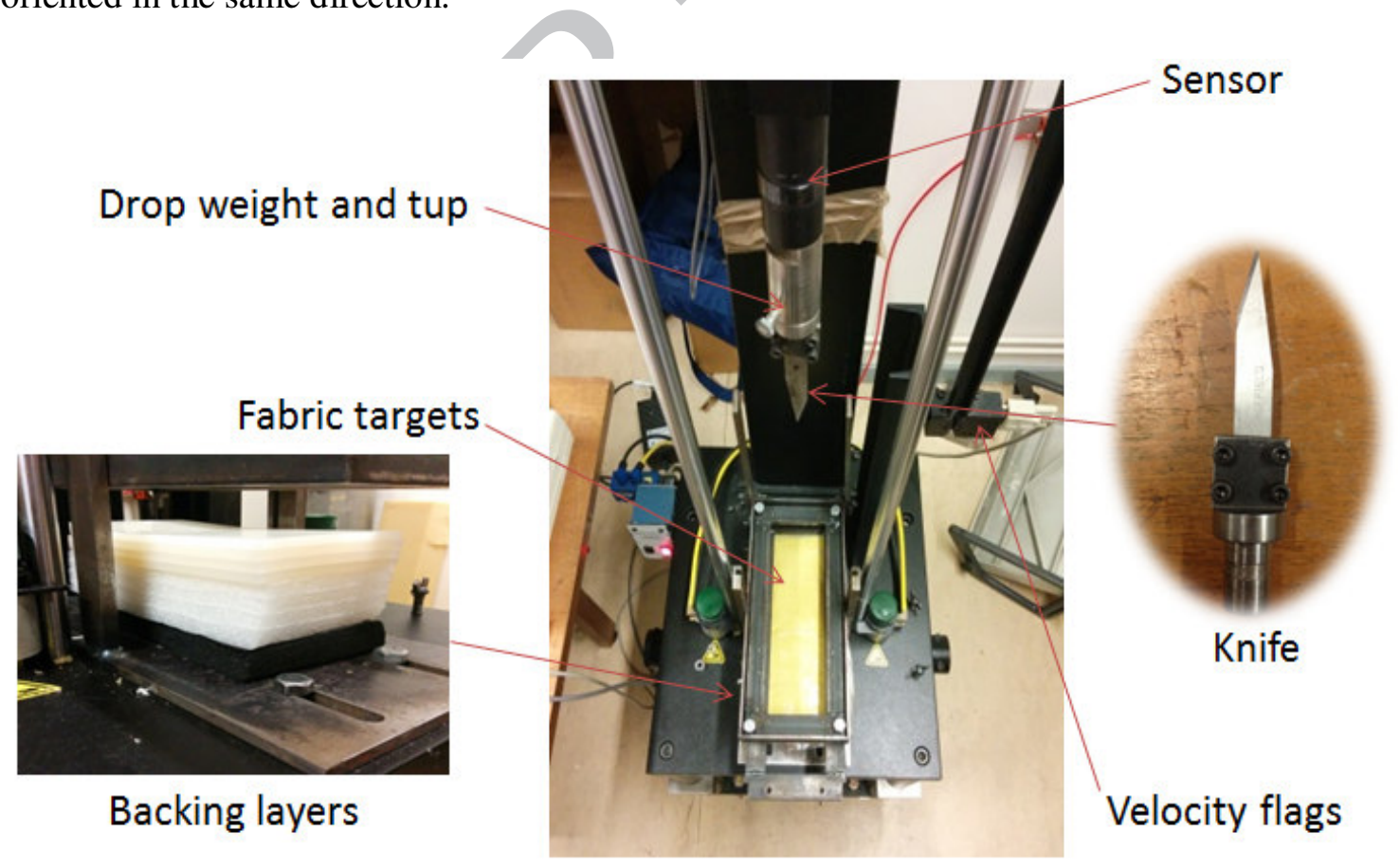

Figure 3. Stabbing test equipment

Untreated Twaron ${ }^{\circledR}$ fabric panels and different types of STF impregnated Twaron ${ }^{\circledR}$ fabric panels were tested with a knife impactor for stabbing resistant performance evaluation based 
on the following test schemes: (1) untreated and impregnated panels with the same number of fabric layers, (2) untreated and impregnated panels with the same areal density, (3) fabric panels impregnated by STFs with different particle sizes, and (4) panels impregnated by STFs with different weight fraction for a STF with a given particle size. Table 2 lists the specimens prepared for stabbing test. For each test, three target specimens were stabbed in order to obtain the average stab performance. Standard deviations are shown in the form of error bars in Figures 5, 6 and 7.

Table 2 Specimens for stabbing test

\begin{tabular}{ccc} 
Target panels & No. of layers & $\begin{array}{c}\text { Areal density } \\
\left(\mathbf{g} / \mathbf{m}^{\mathbf{2}}\right)\end{array}$ \\
\hline Untreated fabric panels - 12L & 12 & 1921.2 \\
Untreated fabric panels - 24L & 24 & 3842.4 \\
20\% 12nm + PEG200 STF impregnated fabric panels & 12 & 3840.3 \\
25\% 12nm + PEG200 STF impregnated fabric panels & 12 & 3844.2 \\
30\% 12nm + PEG200 STF impregnated fabric panels & 12 & 3853.3 \\
20\% 650nm + PEG200 STF impregnated fabric panels & 12 & 3826.7 \\
25\% 650nm + PEG200 STF impregnated fabric panels & 12 & 3823.6 \\
30\% 650nm + PEG200 STF impregnated fabric panels & 12 & 3833.2 \\
\hline
\end{tabular}

\section{Results and Discussions}

\subsection{Rheological property of STFs}

Based on the use of PEG200, silica nanoparticles of $12 \mathrm{~nm}$ and $650 \mathrm{~nm}$ were used to make STFs with weight fractions of $20 \%, 25 \%$ and $30 \%$. Figure 4 displays the rheological responses of different types of STFs in the form of a double logarithmic plot of STF viscosity vs. shear rate.

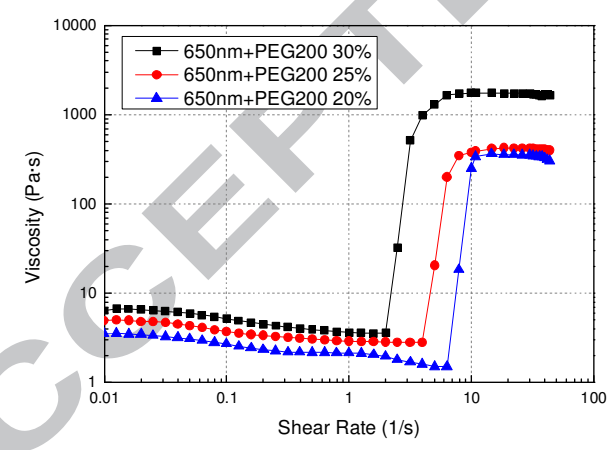

(a) STFs with $650 \mathrm{~nm}$ particles

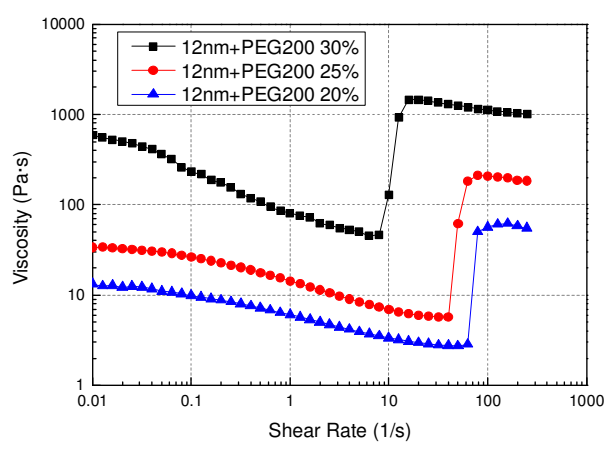

(b) STF with $12 \mathrm{~nm}$ particles

Figure 4. Viscosity against shear rate for STFs with different particle weight fraction

Figure 4 shows that the STFs made from $650 \mathrm{~nm}$ and from $12 \mathrm{~nm}$ silica particles demonstrated obvious viscosity jumps at certain shear rates, the typical shear-thickening phenomenon. In the case of the STF with $30 \%$ of $650 \mathrm{~nm}$ silica particles dispersed into PEG200 as shown in (a), the viscosity after a shear rate of $2 \mathrm{~s}^{-1}$ increased from $2.5 \mathrm{~Pa} \cdot \mathrm{s}$ to $1749 \mathrm{~Pa} \cdot \mathrm{s}$. From both (a) and (b), it is clear that the weight fraction increase of silica particles caused the decrease in critical shear rate, which is the shear rate that triggers the shear thickening, and enhanced the jump of viscosity. The critical shear rate for $650 \mathrm{~nm}$ STFs was between 2 and $6.5 \mathrm{~s}^{-1}$, and that 
for $12 \mathrm{~nm}$ STFs between 8 and $70 \mathrm{~s}^{-1}$. The shear rate, $S$, created with the stabbing was calculated, using Equation (1), to be about $1500 \mathrm{~s}^{-1}$, and this was sufficient to trigger the shear thickening of the STFs created in this research.

$$
S=\frac{v}{d}
$$

In this equation, $v$ is the impact velocity $(3 \mathrm{~m} / \mathrm{s})$ and $d$ is the thickness of the knife, which is $2 \mathrm{~mm}$.

Figure 4 also confirms the influence of the nanoparticle size on the shear thickening behaviour. When smaller particles were used, the critical shear rate became higher and the same time the viscosity jump appeared to be smaller compared to the STF made from $650 \mathrm{~nm}$ particles. In addition, in both cases, the shear-thinning phenomenon was observed, and STFs with smaller particle were noted to have more obvious shear-thinning behaviour.

\subsection{Stabbing resistant properties of fabric panels}

\subsubsection{Introduction}

In the stabbing experiment, the impact velocity was set to be $3 \mathrm{~m} / \mathrm{s}$ representing $22.5 \mathrm{~J}$ impact energy. The corresponding shear rate of the impact was $1500 \mathrm{~s}^{-1}$ as mentioned earlier, and this exceeds the critical shear rate required for the onset of shear thickening of the STFs prepared in this research. STF thickening was expected to be triggered by the knife impact.

Stab tests were carried out on untreated and different types of STF impregnated fabrics. As indicated in Table 1, impact panels were designed on two principles, i.e. the same number of layers and the same areal density. In the same areal density design, 24 layers of untreated Twaron ${ }^{\circledR}$ fabric panels and 12 layers of STF impregnated Twaron ${ }^{\circledR}$ fabric panels were found to have the closest areal density.

In order to study the influence of silica nanoparticle size and particle weight fraction on STF impregnated woven fabric panels, two different silica nanoparticle sizes, i.e. $12 \mathrm{~nm}$ and $650 \mathrm{~nm}$, were chosen to produce the STFs. For each particle size, 3 levels of particle weight fraction, i.e. $20 \%, 25 \%$ and $30 \%$, were employed. The fabrics were fully impregnated using these STFs following the procedure described in Section 2.1.3.

\subsubsection{Influence of STF impregnation}

In order to investigate the effectiveness of STF impregnation with Twaron ${ }^{\circledR}$ fabrics, untreated impregnated panels with the same number of fabric layers were constructed. In parallel to the untreated panel, the 12-layers panels were impregnated with STFs made from $12 \mathrm{~nm}$ and $650 \mathrm{~nm}$ silica particles with different weight fractions, as listed in Table 2. Stabbing test was carried out with these panels, and the panel performance was indicated by the maximum impact load and total energy absorption. Figure 5 compares the stabbing performance of the untreated and impregnated panels with 12 layers of Twaron ${ }^{\circledR}$ fabric. In this comparison, impregnated panels with the lowest $20 \%$ particle weight fraction were used, because of the fact that higher nanoparticle weight fraction in STF leads to better stabbing performance.

It is evident from Figure 5 that the use of STF enhanced the panel performance against stabbing impact regardless of the particle size. Figure 5(a) suggests the maximum load associated to stabbing the STF impregnated panels was almost twice as that of the untreated panel. The increase in maximum load can be attributed to the STF hardening due to the shear 
introduced through the stabbing impact. The shear thickening of the STF made the impregnated panel more energy absorbent, and this clearly illustrated in Figure 5(b). The explanation is that the hardening of the STF turned the concentrated impact force created by knife stabbing into a distributed force, causing an extended area of the panel to be involved in absorbing the impact energy. The untreated panel absorbed about a third of the energy that was taken up by the STF impregnated panels, implying an easier penetration of the knife through the panel. Considering the applied impact energy is $22.5 \mathrm{~J}$, the untreated panel absorbed $20 \%$ of the impact energy. In comparison, the impregnated panels absorbed $64 \%$ $(650 \mathrm{~nm} \mathrm{STF})$ and $58 \%$ (12nm STF) of the impact energy, and were more likely to block the knife piercing.

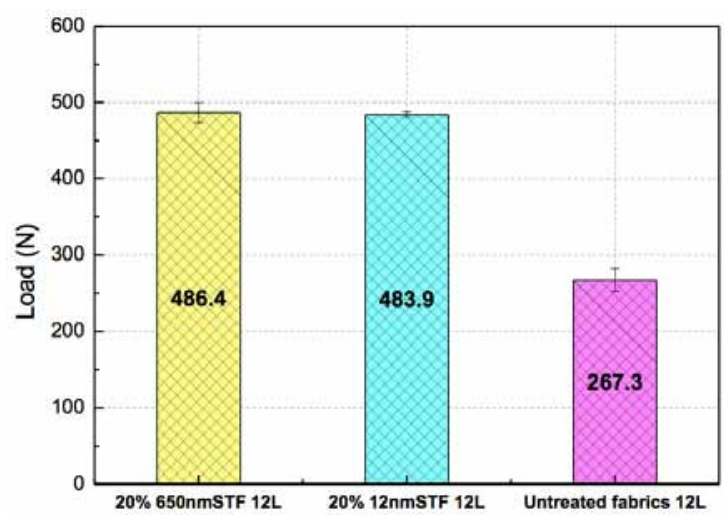

(a) Maximum load

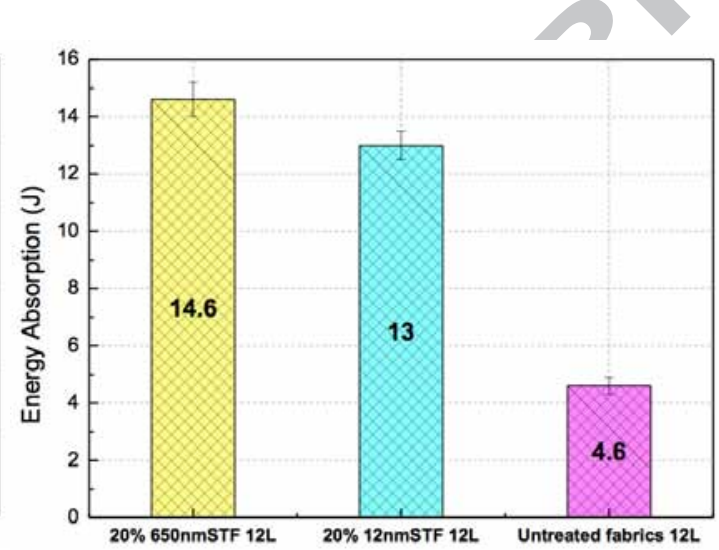

(b) Total energy absorption

Figure 5 Effectiveness of STF impregnation

Coupled with the increase of stabbing performance, attention has to be drawn to the fact that the STF impregnated panels became about twice as heavy as the untreated panel, as indicated in Table 2.

\subsubsection{Reduction of fabric layers in panels}

The previous analysis and discussions indicated that for the panels with the same fabric layers, the impregnated greatly outperformed the untreated. In this exercise, untreated panel and impregnated panels were designed in such a way that they had the same panel weight. The untreated panel was constructed from 24 fabric layers, whereas the STF impregnated panels were made up of 12 fabric layers with full impregnation. The weight of the panels was about $3850 \mathrm{~g} / \mathrm{m}^{2}$, as depicted in Table 2. Figure 6 displays the panel performance against stabbing impact, again using STFs of the lowest particle weight fraction for illustration.

It is clear from Figure 6 that for stabbing panels with same areal density, the STF impregnated panels demonstrated superior performance over the untreated panel in terms of both the maximum load and the total energy absorption. This indicates that for stabbing panel design, the use of STF in the panels could lead to reduced fabric layers to achieve the same or even improved performance against stabbing. In this experiment, it was found that the 12layer impregnated panels demonstrated at least $31 \%$ increase in maximum load and at least $26 \%$ enhancement in total energy absorption than the 24-layer untreated panel. 


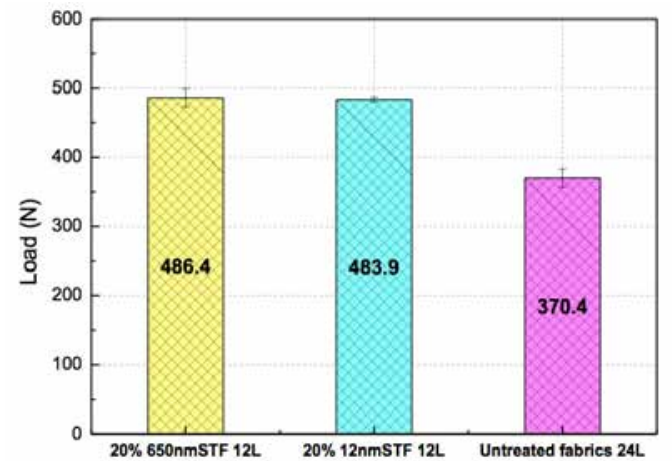

(a) Maximum load

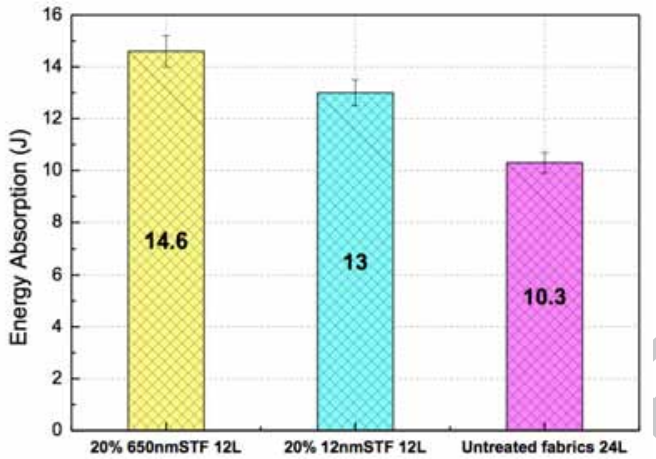

(b) Total energy absorption

Figure 6 Performance of panels with the same areal density

\subsubsection{Nanoparticle size in STF versus performance of stabbing panels}

It was found that STF with larger particle size related to lower critical shear rate and bigger increase in viscosity when triggered by shear loading. Figure 7 shows the performance of impregnated fabric panels with STFs containing $650 \mathrm{~nm}$ and $12 \mathrm{~nm}$ silica particles, all of which were composed of 12 layers of Twaron ${ }^{\circledR}$ fabrics.

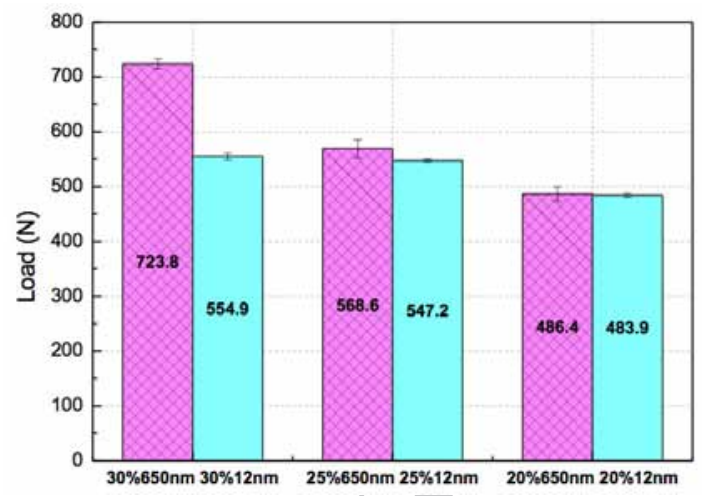

(a) Maximum load

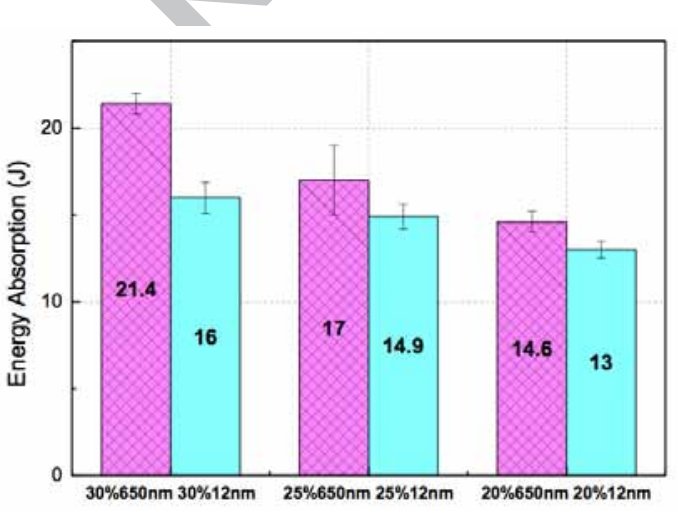

(b) Total energy absorption

Figure 7 Influence of nanoparticle size on panel performance

In terms of both the maximum load and the total energy absorption, 650nm STF led to better performance than the $12 \mathrm{~nm}$ STF regardless of the nanoparticle weight fraction, and the performance differences between the two types of panels became more notable when the nanoparticle weight fraction was bigger, as clearly indicated in Figure 7(a) and 7(b). The difference in energy absorption increased by $12 \%, 14 \%$, and $34 \%$, and that in maximum load increased $0.52 \%, 4 \%$, and $30 \%$, as the particle weight fraction went from $20 \%, 25 \%$, to $30 \%$. These results could be attributed to the more significant hardening effect of the 650nm STF at the particle weight fraction of $30 \%$ when triggered.

\subsubsection{Particle weight fraction on performance of stabbing panels}

The STF made from $650 \mathrm{~nm}$ and $12 \mathrm{~nm}$ silica nanoparticles were created with particle weight fractions of $20 \%, 25 \%$ and $30 \%$. For a given particle size, it was found from earlier discussions that the viscosity increase of the STF became more significant when the particle weight fraction increased in the STF, under a shear loading with shear rate equal to or above the critical shear rate. The impregnated fabric panels with different particle weight fractions were experimented on for their performance against knife impact. Figure 8(a) shows the 
maximum load and (b) the total energy absorption. For both $12 \mathrm{~nm}$ and $65 \mathrm{~nm}$ STFs, the increase in particle weight fraction led to obvious increase in maximum impact load and total energy absorption, as depicted in Figure 8(a) and 8(b) respectively. This confirms that the STF function was fully demonstrated in the STF impregnated fabric panels.

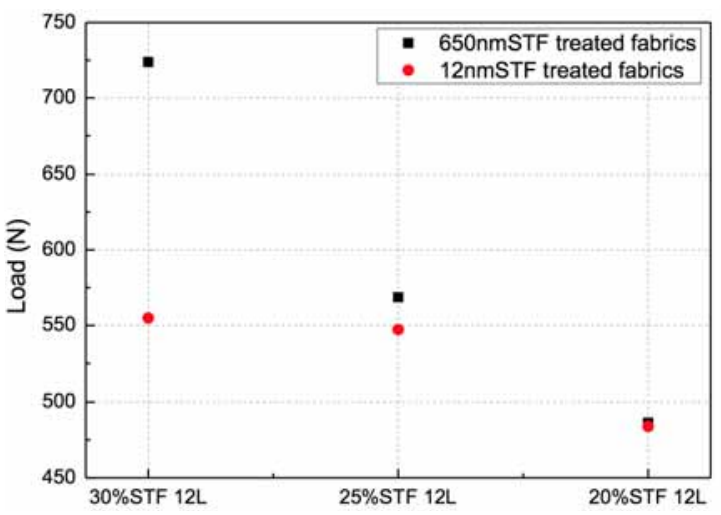

(a) Maximum load

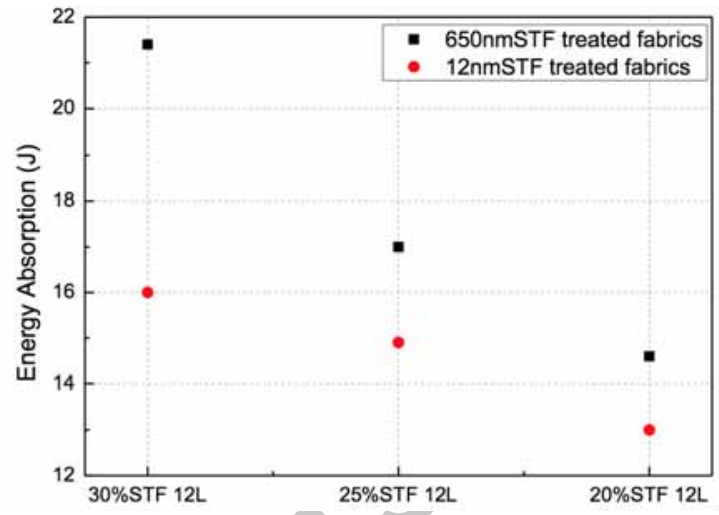

(b) Total energy absorption

Figure 8 Influence of nanoparticle weight fraction on panel performance

\subsubsection{The impact process}

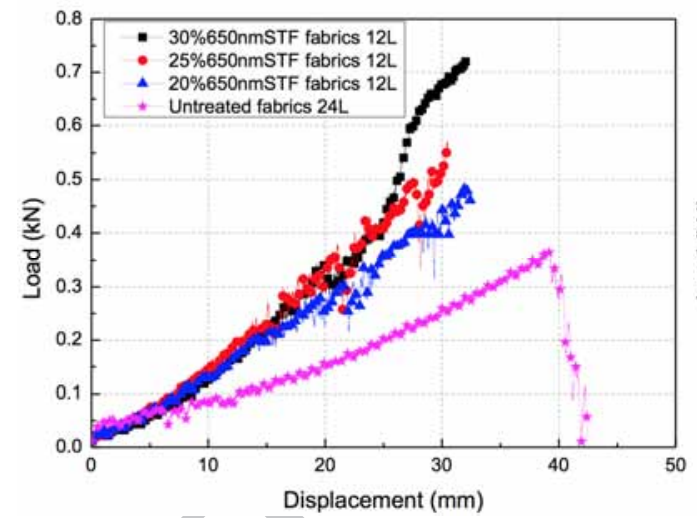

(a) $650 \mathrm{~nm}$ STF panels

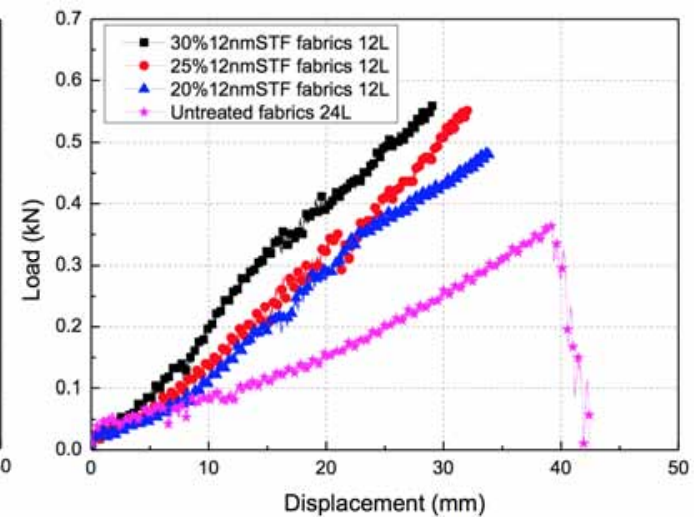

(b) $12 \mathrm{~nm}$ STF panels

Figure 9 Load-deformation curves of STF impregnated panels and the 24-layer untreated panel

Figure 9 records the load-deformation relationships during the stabbing tests, with (a) showing the $12 \mathrm{~nm}$ STF impregnated panels in comparison to the 24-layer untreated fabric panel, and (b) showing the 650nm STF impregnated panels in comparison to the same untreated fabric panel. It can be seen that the 24-layer untreated Twaron ${ }^{\circledR}$ fabric panel produced a maximum load $360 \mathrm{~N}$ before the knife starts to stab into the panel. On the other hand, all the STF impregnated Twaron ${ }^{\circledR}$ fabric panels produced remarkably higher maximum load at the time of panel failure irrespective of the particle size and the particle weight fraction. This is related to the hardening of the STF depicted in the load-displacement curves. Figure 9 also indicated that the deformation depth for the untreated fabric panel is $42 \mathrm{~mm}$, and that for the STF impregnated ones are all below $35 \mathrm{~mm}$. 
It is also found through the experiment that the untreated 24-layer fabric panels were fully penetrated by the knife, whereas only 9 layers were penetrated for the 12-layer panel impregnated with $650 \mathrm{~nm}$ silica STF with $30 \%$ weight fraction. All other STF impregnated panels stopped the knife as well, and the number of layers penetrated fabrics is presented in Table 3. Note that all these panels have the same areal density. This is a major evidence of improvement of stabbing resistant performance of the STF impregnated fabric panels.

Table 3 Layers of fabric penetrated by stabbing impact

\begin{tabular}{|c|c|c|}
\hline Fabric panels & Total layers & Penetration layers \\
\hline 12nm 20\% STF-Twaron ${ }^{\circledR}$ & 12 & 11 \\
\hline 12nm 25\% STF-Twaron ${ }^{\circledR}$ & 12 & 10 \\
\hline 12nm 30\% STF-Twaron ${ }^{\circledR}$ & 12 & 10 \\
\hline $650 \mathrm{~nm} 20 \%$ STF-Twaron ${ }^{\circledR}$ & 12 & 11 \\
\hline $650 \mathrm{~nm} 25 \%$ STF-Twaron ${ }^{\circledR}$ & 12 & 10 \\
\hline 650nm 30\% STF-Twaron ${ }^{\circledR}$ & 12 & 9 \\
\hline Untreated Twaron ${ }^{\circledR}$ & 24 & 24 \\
\hline
\end{tabular}

Improvements in back-face deformation of the STF impregnated panel were also evident in comparison with the untreated fabric panel. The deformation of 24-layer untreated fabric panel formed a cone with a $2.7 \mathrm{~cm}$ depth, whereas the back-face deformation of the $650 \mathrm{~nm}$ $30 \%$-STF impregnated 12-layer panel was hardly noticeable. The comparison between the two is illustrated in Figure 10.

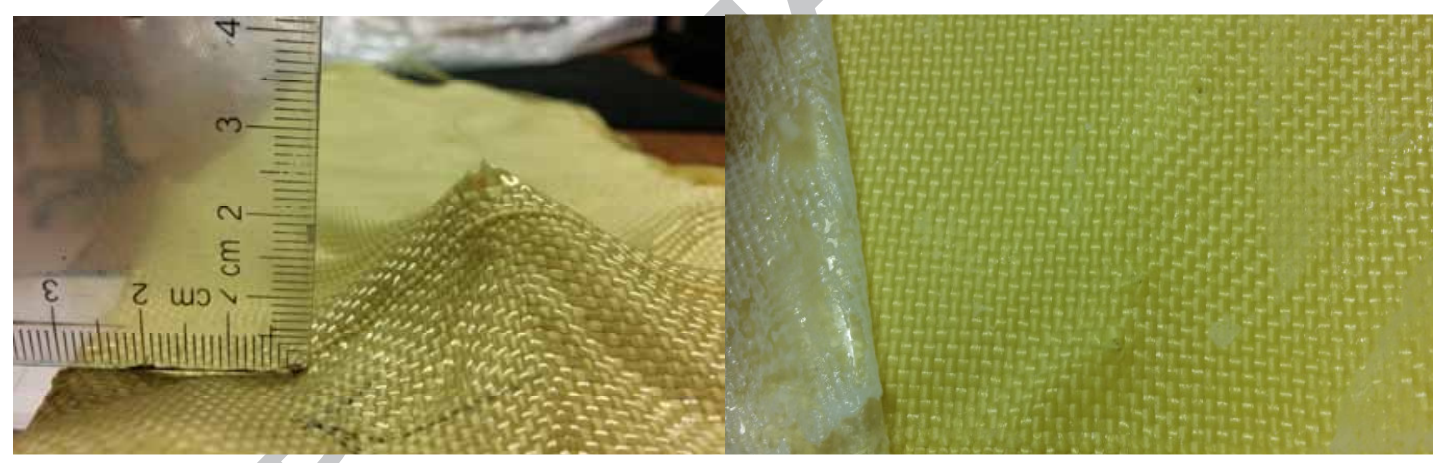

(a) 24-layer of untreated panels

(b) 12-layer STF-impregnated panel

Figure 10 Back-face deformation comparison

\section{Conclusions}

In this research, 6 different types of PEG-silica STFs were prepared, which were used to create 6 different types of STF impregnated stabbing panels with the same areal density, from 12 layers of the same Twaron ${ }^{\circledR}$ fabric. 2 types of untreated stabbing panels were made; the 24-layer had the same areal density as the STF impregnated panels, and the 12-layer had the same number of fabrics as the impregnated counterpart. Knife stabbing test was carried out on Instron Dynatup 8200 drop weight tester with 22.5J impact energy.

From the STF design and preparation, it was confirmed that increase in nanoparticle weight fraction led to reduced critical shear rate and amplified severity of shear thickening viscosity of STF; and that the use of larger silica nanoparticle in the STF contributed to reduction of the critical shear rate and increase of shear thickening viscosity. It was also found that fully impregnated panels with STFs having larger nanoparticle size and higher weight fraction 
resulted in better stab resistant performance in terms of maximum load and total energy absorption.

The work demonstrated that for the 12-layer fabric panels, the impregnated absorbed at least $58 \%$ of the impact energy, compared to the $20 \%$ absorption of the impact energy by the untreated panel. On the basis of the same areal density, the impregnated 12-layer panels outperformed the 24-layer untreated panel. The employment of STF in the panels also significantly reduced the back-face deformation caused by the knife impact. These findings indicate the feasibility of achieving more protective stabbing panels with lower weight and less bulkiness when STF impregnated panels are used against stabbing impact.

\section{Acknowledgements}

The authors are grateful to Teijin Aramid for providing Twaron ${ }^{\circledR}$ fibres used in this research. One of the authors wishes to express her gratitude to Zhongyuan University of Technology, China, for the financial sponsorships for her $\mathrm{PhD}$ study, and to the Chinese Scholarship Committee for the maintenance scholarship.

\section{References}

1. Hearle, J.W., High-performance fibres. 2001, Woodhead Publishing Limited, Cambridge, England : pp. 49.

2. Cheeseman, B.A. and Bogetti, T.A., Ballistic impact into fabric and compliant composite laminates. Composite structures, 2003. 61(1): pp. 161-173.

3. Horsfall, I., Stab Resistant Body Armour. PhD thesis, Cranfield Defence and Security, Shrivenham, Mar 2000 : pp. 51-52.

4. Chadwick, E., Nicol, A.C., Lane, J.V., Gray, T.G., Biomechanics of knife stab attacks. Forensic Science International, 1999. 105(1): pp. 35-44.

5. Zhou, Y., Chen, X. and Wells, G., Influence of yarn gripping on the ballistic performance of woven fabrics from ultra-high molecular weight polyethylene fibre. Composites Part B: Engineering, 2014. 62: pp. 198-204.

6. Gadow, R. and Niessen, K.v., Lightweight ballistic structures made of ceramic and cermet/aramide composites. Ceramic Armor and Armor Systems, Volume 151, 2003: pp. 1-18.

7. Egres Jr, R., Halbach, CJ., Decker, MJ., Wetzel, ED., Wagner, NJ., Stab performance of shear thickening fluid (STF)-fabric composites for body armor applications. development, Proceedings to SAMPE 2005: New horizons for materials and processing technologies, Long Beach, CA. 2005.

8. Chiou, M., Development of protective body armour for puncture, stab and multithreat protection. in Proc Sharp Weapons Armour Technology Symposium. 1999: pp. 2-3.

9. Barnes, H., Shear-thickening ("Dilatancy") in suspensions of nonaggregating solid particles dispersed in Newtonian liquids. Journal of Rheology (1978-present), 1989. 33(2): pp. 329-366.

10. Maranzano, B.J. and Wagner, N.J., The effects of interparticle interactions and particle size on reversible shear thickening: Hard-sphere colloidal dispersions. Journal of Rheology (1978-present), 2001. 45(5): pp. 1205-1222.

11. Lee, Y.S. and Wagner, N.J., Dynamic properties of shear thickening colloidal suspensions. Rheologica Acta, 2003. 42(3): pp. 199-208. 
12. Brown, E. and Jaeger, H.M., The role of dilation and confining stresses in shear thickening of dense suspensions. Journal of Rheology (1978-present), 2012. 56(4): pp. 875-923.

13. Van der Werff, J. and De Kruif, C., Hard-sphere colloidal dispersions: The scaling of rheological properties with particle size, volume fraction, and shear rate. Journal of Rheology (1978-present), 1989. 33(3): pp. 421-454.

14. Srivastava, A., Majumdar, A. and Butola,B., Improving the impact resistance of textile structures by using shear thickening fluids: a review. Critical Reviews in Solid State and Materials Sciences, 2012. 37(2): pp. 115-129.

15. Hasanzadeh, M. and Mottaghitalab, V., The role of shear-thickening fluids (STFs) in ballistic and stab-resistance improvement of flexible armor. Journal of materials engineering and performance, 2014. 23(4): pp. 1182-1196.

16. Ding, J., Tracey, PJ., Li, W., Peng, G., Whitten, PG., Wallace, GG., Review on shear thickening fluids and applications. Textiles and light industrial science and technology, Volume 2 Issue 4, 2013: pp. 161-170.

17. Decker, M., Halbach, CJ., Nam, CH., Wagner, NJ., Wetzel, EG., Wallace, GG., Stab resistance of shear thickening fluids (STF)-treated fabrics. Composites Science and Technology. 2007 Mar 31; 67(3): pp. 565-78.

18. Mahfuz, H., Clements, F., Rangari, V., Dhanak, V., Beamson, G., Enhanced stab resistance of armor composites with functionalized silica nanoparticles. Journal of Applied Physics, 2009. 105(6): pp. 064307-1-7.

19. Wang, Y., Li, S.K. and Feng, X.Y., The Ballistic Performance of Multi-Layer Kevlar Fabrics Impregnated with Shear Thickening Fluids. in Applied Mechanics and Materials. 2015. Trans Tech Publ: 782, pp. 153-157.

20. Majumdar, A., Butola, B.S. and Srivastava, A., An analysis of deformation and energy absorption modes of shear thickening fluid treated Kevlar fabrics as soft body armour materials. Materials \& Design, 2013. 51: pp. 148-153.

21. Tan, V., Tay, T. and Teo,W., Strengthening fabric armour with silica colloidal suspensions. International Journal of Solids and Structures, 2005. 42(5): pp. 15611576.

22. Park, Y., Kim, Y., Baluch, A.H., Kim, C.G., Empirical study of the high velocity impact energy absorption characteristics of shear thickening fluid (STF) impregnated Kevlar fabric. International Journal of Impact Engineering, 2014. 72: pp. 67-74.

23. Park, J.L., Yoon, B.I., Paik, J.G., Kang, T.J., Ballistic performance of p-aramid fabrics impregnated with shear thickening fluid; part I-effect of laminating sequence. Textile Research Journal, 2011. 82(6): pp. 527-541.

24. Yang, Y. and Chen, X., Study of energy absorption and failure modes of constituent layers in body armour panels. Composites Part B: Engineering, 2016. 98: pp. 250-259.

25. Wetzel, E.D., Lee, Y.S., Egres, R.G., Kirkwood, K.M., Kirkwood, J.E., Wagner, N.J., The effect of rheological parameters on the ballistic properties of shear thickening fluid (STF)-Kevlar composites. Proceedings to NUMIFORM 2004. Columbus, OH, 712(1): pp. 288-293. INSTITUTE OF PHYSICS PUBLISHING LTD.

26. https://www.alfa.com/en/catalog/B21918/, access date: 22/10/2016.

27. Chow, M. and Zukoski, C., Gap size and shear history dependencies in shear thickening of a suspension ordered at rest. Journal of Rheology (1978-present), 1995. 39(1): pp. 15-32.

28. Walker, C.A., Gray T.G., Nicol A.C., Chadwick E.K., Evaluation of test regimes for stat-resistant body armour. Proceedings of the Institution of Mechanical Engineers, Part L, Journal of Materials Design and Applications, 2004 Oct. 1; 218(4): pp. 355361. 